\title{
A formação do professor de línguas estrangeiras: imaginários em torno do ensino e da aprendizagem ${ }^{1}$
}

\author{
Carmen Terezinha Baumgartner \\ Leandro Wallace Menegolo \\ Vitor Emanuel Sguarezi Marangoni \\ Universidade Estadual do Oeste do Paraná - UNIOESTE -, Cascavel-PR
}

\begin{abstract}
Resumo
Este trabalho é o resultado de uma pesquisa na área da Linguística Aplicada, que estudou crenças sobre a docência da língua estrangeira. Um grupo de alunos iniciantes de um curso de licenciatura em Letras, de uma universidade pública, localizada na região Oeste do Paraná, as avaliou em um questionário. O objetivo foi refletir sobre essas crenças e quais suas implicações na formação acadêmica. A metodologia adotada classificou-se como pesquisa qualitativa, aplicada, exploratória e de campo. Analisando as crenças mais assumidas pelo grupo participante, concluiuse que esses alunos estão em conformidade com as contribuições recentes da Linguística Aplicada, mesmo não tendo sido expostos a nenhuma delas no ambiente universitário, demonstrando a existência de uma conscientização acerca do que é ensinar e aprender uma língua estrangeira. Além disso, a maioria das crenças depositava em algo exterior ao indivíduo o crédito da responsabilidade pelo aprendizado da língua estrangeira.
\end{abstract}

Palavras-chave: Crenças. Ensino. Aprendizagem. Linguística Aplicada.

\begin{abstract}
This article, the result of research in the field of Applied Linguistics, studies beliefs about the teaching of foreign languages. A group of beginner students in an undergraduate course in language at a public university located in the western region of Paraná evaluated beliefs in a questionnaire. The objective was to reflect on these beliefs and their implications in teacher education. The adopted methodology is classified as qualitative, applied, exploratory and field research. Analyzing the most assumed beliefs of the participating group, it was concluded that these students are in accordance with the recent contributions of Applied Linguistics, even though they have not been exposed to any of them in the university environment. This shows there is an awareness about what teaching and learning a foreign language is. In addition, most of the beliefs credited something outside the individual for the responsibility of learning the foreign language.
\end{abstract}

Keywords: Beliefs. Teaching. Learning. Applied Linguistics.

\footnotetext{
${ }^{1}$ Agradecemos a CAPES pela concessão das bolsas de estudo, o que possibilitou a realização desta pesquisa. Os três autores pertencem ao grupo de pesquisa "Linguagem, Cultura e Ensino" e ao programa de pós-graduação stricto sensu em Letras da UNIOESTE.
} 


\section{INTRODUÇÃO}

Estudamos a relação entre a Educação e a Linguagem, mais especificamente, refletimos sobre as crenças ${ }^{2}$ acerca do ensino ${ }^{3}$ e da aprendizagem ${ }^{4}$ de Línguas Estrangeiras (doravante LE) mais aparentes nas representações de ingressantes (alunos do $1 .^{\circ}$ ano) de um curso de graduação em Letras/licenciatura, de uma universidade pública, localizada no Oeste do Estado do Paraná, no ano de 2017, com aportes da Linguística Aplicada (adiante LA), estabelecendo, assim, os limites contextuais deste trabalho.

As reflexões que desenvolvemos endereçam-se a estudantes e aos professores de LE das escolas públicas, particulares e cursos livres, pois é a partir dos modos de pensar a ação docente que se constroem e se dinamizam as aulas de LE.

Levando em conta o panorama exposto anteriormente, a pergunta fundamental para a qual avaliamos a necessidade de busca de uma resposta é "quais as implicações das crenças sobre o ensino e a aprendizagem de LE, segundo a LA, mais assumidas por alunos do primeiro período do curso de licenciatura em Letras?".

Nesse sentido, o objetivo é refletir sobre a interferência, consoante com a LA, das crenças mais admitidas pelos ingressantes que almejam a licenciatura para a docência da LE.

Metodologicamente, orientando-nos por Gil (2010, p. 26), este estudo situa-se na área de Linguística, Letras e Artes do CNPQ, subárea de LA. Conforme sua finalidade, enquadra-se como pesquisa aplicada por ser voltada "à aquisição de conhecimentos com vistas à aplicação numa situação específica" (p. 27). Conforme seus objetivos mais gerais, coloca-se como exploratório, porque a maior familiaridade com o problema torna-o mais explícito. Coincidindo com os métodos empregados, trata-se de uma pesquisa quanti-qualitativa e de campo pela natureza e ambiente em que os dados foram gerados e analisados.

Primeiramente, levantamos as crenças sobre o ensino e a aprendizagem de LE, advindas dos trabalhos de Moita Lopes (2002, p. 65) e de Barcelos (2004; 2007), discutidas em nossas

\footnotetext{
2 Neste trabalho, o termo "crença" significa "aquilo em que se crê" (HOUAISS, 2009). Não traduz nem uma verdade, nem uma mentira, mas um mero ponto de vista que será escrutinado pelas lentes da Linguística Aplicada. Apenas, uma forma de pensamento que é adotada por um grupo de pessoas e que nela acreditam. O mesmo vale para todos os sinônimos empregados para a ele se referir (visão, opinião, ponto de vista, convicção, maneira de acreditar etc.).

3 "Ensino", aqui e adiante, significa "o exercício do professorado; magistério", segundo Houaiss (2009).

4 "Aprendizagem", aqui e doravante, significa, conforme Houaiss (2009), "ato ou efeito de aprender", "adquirir conhecimento (de), a partir de estudo; instruir-se".
} 
aulas na disciplina de LA. Extraímos 25 crenças e as reunimos num questionário. Ao aplicarmos numa turma de 46 ingressantes, indagamos o quanto esses estudantes acreditavam nelas, solicitando que respondessem sobre cada uma numa escala de $0 \%$ a $100 \%$. Para podermos tabular os dados, oferecemos 5 possibilidades fechadas de resposta previamente estabelecidas: $0 \%, 25 \%$, $50 \%, 75 \%$ e $100 \%$.

Depois de analisadas, o próximo passo foi o de reagrupar essas 25 crenças por meio de um critério: a quantidade de manifestações recebidas por cada crença. Criamos 3 grupos: o das crenças nada influentes, os de pouca e os de muita influência.

Após traçar as linhas delimitantes e que dão configuração aspectual à pesquisa, o passo seguinte foi fazer o registro e organização desses dados, seguido da análise das crenças, buscando respostas para o questionamento levantado.

\section{CONVICÇÕES E REFLEXOS DIDÁTICO-PEDAGÓGICOS}

Mostramos, nesta seção, em que medida a lista de crenças submetidas à apreciação do Ensino Superior em Letras são assumidas, em três níveis, pelos ingressantes.

\section{Crenças nada influentes}

Iniciemos pela constatação das crenças que não estão interferindo, atualmente, no desempenho didático desses ingressantes, expostas no Quadro n. ${ }^{\circ} 1$.

Quadro 1: Relação das crenças nada influentes.

\begin{tabular}{|c|c|c|c|c|c|c|}
\hline \multirow[b]{2}{*}{ N. ${ }^{\circ}$} & \multirow[b]{2}{*}{ Afirmação } & \multicolumn{5}{|c|}{ Escala } \\
\hline & & $\mathbf{0 \%}$ & $25 \%$ & $50 \%$ & $75 \%$ & $100 \%$ \\
\hline 12 & Aprender LE é apropriado somente para os ocupantes da classe economicamente alta. & 46 & 0 & 0 & 0 & 0 \\
\hline 4 & $\begin{array}{l}\text { Os alunos da escola pública são desinteressados e por isso só se deve ensinar coisas fáceis e } \\
\text { básicas. }\end{array}$ & 44 & 1 & 0 & 1 & 0 \\
\hline 3 & Quem não "sabe" a Língua Portuguesa (adiante LP) não pode aprender uma LE. & 36 & 8 & 2 & 0 & 0 \\
\hline 19 & $\begin{array}{l}\text { A LE correta é aquela falada no país de maior prestígio econômico (por exemplo, o inglês norte- } \\
\text { americano ou estadunidense). }\end{array}$ & 34 & 8 & 2 & 1 & 1 \\
\hline 13 & É preciso falar como um falante nativo para que se aprenda uma LE. & 31 & 7 & 1 & 4 & 0 \\
\hline
\end{tabular}

Fonte: Material de geração de dados.

Analisando esses dados, percebemos que, ao somarmos os valores constantes nas colunas de $50 \%, 75 \%$ e 100\% (que configuram escalas de forte interferência), essas crenças apenas alcançaram de 1 a 5 manifestações dos ingressantes. Esses números correspondem de 2,2\% a 
10,9\% de aceitação dessas crenças.

Por esses resultados, entendemos serem crenças que pouco ou nada interfeririam, atualmente, no desempenho didático desses alunos ou por terem sido superadas ou por nunca terem sido consideradas.

\section{Crenças pouco influentes}

Outras crenças demonstraram ter de baixa a média relevância no desempenho didático dos alunos em questão, mostradas no quadro 2.

Quadro 2: relação das crenças pouco influentes

\begin{tabular}{|c|c|c|c|c|c|c|}
\hline \multirow[b]{2}{*}{ N. ${ }^{o}$} & \multirow[b]{2}{*}{ Afirmação } & \multicolumn{5}{|c|}{ Escala } \\
\hline & & $\mathbf{0 \%}$ & $25 \%$ & $\mathbf{5 0 \%}$ & $75 \%$ & $100 \%$ \\
\hline 5 & Saber LE é ter o domínio perfeito sobre essa LE. & 26 & 14 & 3 & 2 & 1 \\
\hline 2 & Mulheres têm mais facilidades do que homens na aprendizagem de LE. & 30 & 4 & 11 & 1 & 0 \\
\hline 24 & O uso da Língua Portuguesa é prejudicial para o ensino da LE por causa da sua interferência. & 29 & 11 & 5 & 1 & 0 \\
\hline 23 & A tradução como solução pedagógica é prejudicial à aprendizagem de LE. & 12 & 18 & 9 & 4 & 3 \\
\hline 17 & Um professor de LE precisa, necessariamente, ter vivido ou estudado no exterior. & 33 & 7 & 3 & 2 & 1 \\
\hline 16 & É preciso ir ao exterior para se aprender LE. & 30 & 9 & 6 & 1 & 0 \\
\hline 8 & Só se aprende LE em cursos livres (particulares) de idiomas. & 34 & 5 & 5 & 2 & 0 \\
\hline 9 & Não é possível aprender LE em escolas públicas. & 28 & 7 & 6 & 3 & 2 \\
\hline 20 & $\begin{array}{l}\text { A LE correta é aquela falada no país de origem dessa LE (por exemplo, o inglês britânico, falado } \\
\text { na Inglaterra). }\end{array}$ & 32 & 7 & 4 & 2 & 1 \\
\hline 15 & A maioria dos professores de LE não a falam e tem um conhecimento muito limitado dessa LE. & 19 & 17 & 8 & 1 & 1 \\
\hline 7 & Não se aprende LE no curso universitário de Letras. & 24 & 8 & 12 & 1 & 1 \\
\hline
\end{tabular}

Fonte: Material de geração de dados.

Ao somarmos os valores constantes nas colunas adiante de $50 \%$ (que configuram escalas de alta interferência), essas crenças receberam de 6 a 20 manifestações. Esses valores correspondem de $13 \%$ a 43,5\% do nível de apropriação da turma, mas demonstram interferência de grau irrelevante.

\section{Crenças influentes}

Por fim, houve crenças que são bastantes assumidas pelos ingressantes, manifestadas no Quadro 3. 
Quadro 3: Relação das crenças influentes.

\begin{tabular}{|c|c|c|c|c|c|c|}
\hline \multirow[b]{2}{*}{ N. ${ }^{\mathbf{2}}$} & \multirow[b]{2}{*}{ Afirmação } & \multicolumn{5}{|c|}{ Escala } \\
\hline & & $\mathbf{0 \%}$ & $25 \%$ & $50 \%$ & $75 \%$ & $100 \%$ \\
\hline 21 & A sala de aula também é o lugar adequado para se conversar sobre a aprendizagem da LE. & 1 & 2 & 5 & 4 & 34 \\
\hline 22 & $\begin{array}{l}\text { Para se ensinar uma LE tem-se que necessariamente ensinar as quatro habilidades linguísticas: } \\
\text { ouvir, falar, ler e escrever. }\end{array}$ & 2 & 2 & 5 & 6 & 31 \\
\hline 18 & A maioria das pessoas em meu país acredita que é importante saber falar a Língua Inglesa. & 4 & 4 & 5 & 15 & 18 \\
\hline 25 & É impossível se ensinar uma LE sem transmitir aspectos culturais dessa LE. & 5 & 4 & 6 & 8 & 23 \\
\hline 1 & $\begin{array}{l}\text { Uma criança (até } 11 \text { anos) aprende mais facilmente uma língua estrangeira (doravante LE) do que } \\
\text { um adulto. }\end{array}$ & 5 & 1 & 12 & 17 & 11 \\
\hline 11 & A lotação da sala de aula de escola pública interfere no processo ensino-aprendizagem da LE. & 4 & 7 & 6 & 13 & 16 \\
\hline 6 & O aluno tem que aprender a pensar em LE para aprendê-la. & 3 & 7 & 11 & 13 & 12 \\
\hline 10 & O próprio funcionamento do sistema público não possibilita o ensino eficaz da LE. & 6 & 12 & 8 & 11 & 9 \\
\hline 14 & Ter um professor nativo em LE favorece o seu aprendizado. & 7 & 12 & 11 & 10 & 4 \\
\hline
\end{tabular}

Fonte: Material de geração de dados.

Essas crenças, no Quadro 3, receberam de 21 (45,7\%) a 46 (100\%) manifestações, nessa turma iniciante, na somatória dos valores nas colunas acima de 50\%.

Como se tratam de números que advieram de exposições de mais da metade da turma, concentramo-nos na análise dessas crenças e, assim, respondemos ao objetivo de quais são as mais aparentes e, adiante, em que medida elas influenciam (ou influenciariam) no aprendizado individual de uma LE e no desempenho didático coletivo, segundo as contribuições da LA.

A crença $n .^{\circ}$ 21, “A sala de aula também é o lugar adequado para se conversar sobre a aprendizagem da LE", teve as seguintes avaliações: 5 creem parcialmente nela (50\%); 4 estão mais propensos a acreditar nessa afirmação (75\%) e 34 acreditam totalmente nessa assertiva $(100 \%)$.

Quanto a esse aspecto, Barcelos (2007, p. 131) manifesta-se da seguinte forma: "A sala de aula não é somente o lugar para se aprender língua materna ou estrangeira. É também o lugar para se aprender a pensar sobre a aprendizagem ou sobre fatores desse processo, como as crenças, os estilos e as estratégias de aprendizagem e suas mudanças”. Portanto, é preciso refletir sobre o que se acredita, principalmente graduandos em Letras, que em breve serão professores de LE.

Cruz (2015, p. 29) é de opinião semelhante. Para ela, “O pensar criticamente sobre a relação teoria e prática possibilitaria ao profissional da área pedagógica [...] avançarem [sic], concretamente, rumo à transformação de sua prática educativa e a sua própria transformação como intelectual crítico".

Ramos (2011, p. 46-47) segue a mesma tendência, ao argumentar em favor da constante necessidade de reflexão e mudança em sala de aula. Tais atitudes são pertinentes à classe docente.

A crença n. 22 do questionário foi "Para se ensinar uma LE tem-se que necessariamente 
ensinar as quatro habilidades linguísticas: ouvir, falar, ler e escrever”. Dos calouros, 5 estão na média (50\%); 6, arriscam-se mais (75\%); 31 não têm dúvidas $(100 \%)$.

Em Marzari (2013, p. 1-2), constatou-se a inexequibilidade da meta de se ensinar por meio do desenvolvimento das quatro habilidades linguísticas, apesar de esforços notáveis dos professores nas escolas regulares brasileiras.

Para Moita Lopes (2002, p. 130), seria legítimo que o professor de LE priorizasse a habilidade de leitura por ser essa "[...] a única habilidade que atende às necessidades educacionais que o aprendiz pode usar em seu próprio meio [...] e que pode continuar a usar autonomamente ao término de seu curso de LE". Todavia, embora essa habilidade possa ser priorizada, entende-se que ela não ocorre deslocada ou independente das demais. Assim, pode-se dar ênfase a ela, mas, para realizá-la, é necessário recorrer à escrita, principalmente para compreender o que a caracteriza e como estão estruturados os textos em uma LE. A formação de um bom leitor em LE está associada aos conhecimentos de mundo, textuais e linguísticos desse leitor.

A crença n. 18 foi "A maioria das pessoas em meu país acredita que é importante saber falar a língua inglesa". Da turma, 5 estão mais ou menos convencidos disso, um pouco (50\%); 25 , mais próximos do convencimento e 18 admitem plenamente essa visão (100\%).

Informações do Instituto de Pesquisas Plano CDE (2014, p. 14) dão conta de que o inglês é o idioma dominante, sendo utilizado em $91 \%$ das consecuções de negócios internacionais.

A alegação dos entrevistados é de que o inglês é "indispensável para a inserção e a ascensão no mercado de trabalho" (Instituto de Pesquisas Plano CDE, 2014, p. 18-19), para o surgimento de oportunidades de contratação, melhoria nas possibilidades de aumento salarial e promoção funcional. Essa afirmação aponta estar intrinsecamente ligada ao caráter mercadológico do mundo globalizado, principalmente pelos entrevistados integrantes das classes baixa e média. Todavia, a pesquisa expõe claros indícios de que esse esforço de compreensão ainda está por se realizar, pois existe uma carência de ajustes entre o cotidiano dos que querem aprender um novo idioma e a atual oferta dos locais e métodos de ensino.

De acordo com Terra (2008), outro contexto intensificador dessa afirmação se deve ao fato de, principalmente, a Língua Inglesa (LI), tida como língua mundial, conquistar, frequentemente, mais espaços nos mais variados campos da atividade humana (informática, TV, filmes, jogos, culinária, expressões do dia-a-dia, músicas), revelando que o status ocupado pelo inglês na conjuntura nacional e internacional seja indubitável. 
A crença n. ${ }^{\text {o }} 25$ foi "É impossível se ensinar uma LE sem transmitir aspectos culturais dessa LE". Do grupo de ingressantes, 6 assumem mais ou menos; 8, com mais confiança (75\%); 23, sem a menor sombra de dúvida (100\%).

Dema e Moeller (2012) relacionam vários estudos (Brown, 2007 \& Kramsch, 1998, Kuang, 2007, Savignon \& Sysoyev, 2005, Schulz, 2007, Tang, 1999 apud Dema \& Moeller, 2012 p. 76), nos quais a conclusão é que a língua e a cultura são melhores adquiridas em conjunto. Tal inter-relação é descrita como inseparável, pois a aquisição de um novo idioma implica em incorporar uma nova ou mais culturas. Embora as LEs possam deixar de ser ensinadas através de exercícios e diálogos artificiais, até meados da década de 1980, os aspectos culturais eram ensinados separadamente e não integrados ao processo de aprendizagem de LEs. Devido à complexidade em se definir o termo "cultura", a grande preocupação remanescente é encontrar maneiras efetivas de desenvolver habilidades comunicativas e colaborativas no século XXI.

A crença n. ${ }^{\circ} 1$ do questionário foi "Uma criança (até 11 anos) aprende mais facilmente uma língua estrangeira (doravante LE) do que um adulto". Da turma, 12 (50\%) acreditam medianamente; 17 (75\%) creem altamente e 11 (100\%), totalmente.

Basicamente, esse argumento se origina a partir de pesquisas feitas nos anos 1950 e 1960 que categorizaram a aprendizagem adulta como período crítico, onde o cérebro adulto se encontraria inflexível a novos processos sistêmico-neurais de aprendizagem, enquanto as crianças possuiriam cérebros mais flexíveis (Lenneberg, 1967; Penfield; Roberts, 1959; Pizzolato, 1995). As crianças aprendem línguas mais facilmente porque o córtex infantil é mais plástico do que o dos aprendizes adultos.

A hipótese do período crítico tem sido questionada por muitos pesquisadores nos últimos anos, e é bastante controversa (Genesee, 1981; Harley, 1989; Newport, 1990). A evidência para a base biológica do período crítico foi desafiada, e a mais recente argumentação revela que as diferenças podem refletir fatores psicológicos e sociais, muito além dos fatores meramente biológicos, o que proporcionaria uma melhor aprendizagem por parte das crianças. Por exemplo, as crianças são mais motivadas a aprender uma segunda língua do que os adultos provavelmente há mais incentivo nos ambientes de entretenimento infantil, mídia e escola para que as crianças se comuniquem em uma segunda língua do que para os adultos se comunicarem na mesma em seus ambientes de trabalho e convívio social.

Contudo, pesquisas experimentais têm demonstrado uma inferioridade do aprendizado das 
crianças em condições controladas. Mesmo quando os métodos de ensino parecem favorecer o aprendizado em crianças, elas se comportam de modo inferior do que adolescentes e adultos (Asher \& Price, 1967).

Um aspecto da aprendizagem de línguas onde a hipótese sobre quanto mais jovem, melhor, pode ter pontos positivos no quesito pronúncia e sotaque. De acordo com Ramirez, Yuen e Ramey (1991), uma série de estudos descobriu que a criança mais jovem, ao começar a aprender uma segunda língua, supera o sotaque nessa língua (Asher \& Garcia, 1969; Oyama, 1976). Isso se deve ao fato da pronúncia envolver padrões motores já fossilizados na primeira língua e difíceis de alterar após uma certa idade, devido à natureza dos mecanismos neurofisiológicos envolvidos. Os autores ponderam a possibilidade de ainda não se saber como ensinar fonologia em uma segunda língua, o que leva à necessidade de pesquisas emergenciais que desenvolvam métodos nessa área.

O levantamento de Ramirez et al. (1991) sugere que as crianças mais velhas mostram ganhos mais rápidos, embora as crianças mais novas possuam uma vantagem na pronúncia. Certamente as crianças que começam a aprender uma segunda língua no jardim de infância ou ensino fundamental estão mais expostas a essa língua do que as que começam na quinta ou sexta série. Mas a exposição em si não prevê a aquisição plena de todos os aspectos da língua.

A crença n." 6 foi "O aluno tem que aprender a pensar em LE para aprendê-la". Os ingressantes demonstraram confiança nessa forma de crer na medida de 11 acreditarem medianamente (50\%); 13 estão propensos a defendê-la (75\%) e 12 confiam plenamente (100\%).

Uma das perguntas sobre o bilinguismo é se aprender uma LE faz com que pensemos de forma diferente. Consoante com Pinker (2007), essa questão está ligada à sempre controversa hipótese de Sapir e Whorf, comumente entendida como as línguas que falamos afetam a nossa maneira de pensar. Os debates acalorados sobre tais efeitos têm colocado os estudiosos e os leigos uns contra os outros durante mais de um século, com respostas que vão desde "não pensamos em linguagem" até "pensamos de forma diferente dependendo da linguagem" (Pinker, 2007). O pensamento não é um fenômeno unitário - pensamos de muitas maneiras, algumas das quais envolvem as línguas e outras não, conforme Pinker (2007). Em Sapir e Whorf (apud Pinker, 2007), o argumento era de que as línguas que falamos nos oferecem ferramentas cognitivas que nos ajudam a pensar. A linguagem não é a única maneira pela qual pensamos, embora ela seja essencial para codificar novos relacionamentos, categorias e fenômenos. Quando o ser humano 
fala seu idioma materno, está obedecendo a regras gramaticais já tão aprendidas que, por sua velocidade de prática oral, não as percebe, pois estão sendo automaticamente executadas. Tal habilidade pode ser desenvolvida no aprendizado da LE, mas a diferença na automaticidade do uso da LM e da LE obriga-nos a reconsiderar a maneira como discutimos o pensamento em LE: não é a LE que nos faz pensar de forma diferente. Somos nós, aprendizes de LE, que precisamos fazer esforços conscientes para mudar a maneira como pensamos com a finalidade de sermos entendidos e compreendidos na LE e, assim, aprendê-la.

E quanto à "voz interior", cuja existência é mencionada por alguns aprendizes? Para Pinker (2007), a experiência de se ouvir "pensando" na nova linguagem seria personificação do "pensar na LE". A realidade, no entanto, é mais complexa e menos dramática. A "nova" voz do discurso interior não é uma garantia de que auxiliamos e categorizamos de forma semelhante aos falantes da LE. Podemos ainda falar do modo da LM na LE. Da mesma forma, não se ouvir "pensando na LE" não significa não estarmos pensando nela.

Madeira (2008) entende esse modo de pensar a aprendizagem como um conceito inadequadamente adquirido, resultado de noções propagadas pela mídia e/ou pela cultura popular, cujo resultado nem sempre colabora para a aprendizagem da LE. Ao invés, pode até interrompêla, servindo mais como fator inibidor da motivação para o aprendiz.

Talvez, esse conceito seja herança do método direto intuitivo. Ao assumir o governo, em 1930, Getúlio Vargas criou o Ministério da Educação e Saúde e as Secretarias de Educação nos Estados (Romanelli, 2003). No que tange ao ensino de línguas, as diretrizes adotadas para as disciplinas de línguas vivas estrangeiras (francês, inglês e alemão), pela primeira vez, estabeleceram oficialmente a adoção do "método direto intuitivo", o qual consistiu em ensinar a LE na própria LE, entre outros atributos. O Método Direto foi instituído pelo Decreto n. ${ }^{\circ}$ 20.833, de 21.12.1931, como método oficial de ensino das línguas vivas estrangeiras (francês, inglês e alemão).

A forma de crer n. ${ }^{\circ} 10$ foi "O próprio funcionamento do sistema público não possibilita o ensino eficaz da LE”. Para os ingressantes, 8 acreditam parcialmente na afirmação (50\%); 11 são mais propensos $(75 \%)$ e 9 concordam (100\%). Dela deriva a maneira de acreditar n $\mathrm{n}^{\mathrm{o}} 11$, "A lotação em sala de aula de escola pública interfere no processo ensino-aprendizagem da LE”. Dos alunos ingressantes, 6 creem em mediania (50\%), 13, com propensão (75\%) e 16, completamente (100\%). 
Conforme o exame do Instituto de Pesquisas Plano CDE (2015b), após cinco etapas de pesquisa, por meio de entrevistas e dinâmicas com gestores públicos, 1.269 professores e coordenadores pedagógicos, os problemas mais apontados foram os seguintes: excesso de alunos em sala de aula nas escolas públicas, condições de contratação (27\% dos professores da rede pública nacional são temporários e a instabilidade contratual não propicia a criação de vínculos entre professor e alunos), acesso a recursos didáticos adequados, 69\% dos professores se dedicam a mais de 6 turmas por semana e $65 \%$ lecionam mais de uma disciplina enquanto apenas 35\% se dedicam apenas à LE, carga horária insuficiente, falta de plano estratégico comum para o aprendizado da língua e irrelevância do ensino de LE dentro da base curricular. O estudo concluiu que, enquanto for vista como uma disciplina complementar, o inglês não será desenvolvido de forma adequada nas escolas públicas, o que prejudica a inserção do Brasil em um contexto globalizado (Instituto de Pesquisas Plano CDE, 2015b).

A crença n. ${ }^{\circ} 14$ foi "Ter um professor nativo em LE favorece o seu aprendizado". 11 ingressantes defendem que tem importância média $(50 \%) ; 10$, com propensão (75\%) e 4 entendem que o aprendizado de uma LE está em estreita dependência de que o professor seja um falante nativo $(100 \%)$.

Dados da pesquisa elaborada pelo Instituto de Pesquisa Data Popular (2014, p. 5; 26) apontam os atributos mais importantes para um professor de inglês na seguinte ordem: possuir horários flexíveis, propor atividades complementares, ser exigente, a qualidade de ser de outro país, ter curso superior ou especialização e ser formado pela própria escola. Essa crença está, às vezes, ligada a outras duas: é preciso ir ao exterior para se aprender LE e um professor de LE precisa, necessariamente, ter vivido ou estudado no exterior.

Madeira (2008, p. 124) atribui à mídia e/ou à cultura popular a fonte de geração de crenças. Na opinião do autor, "slogans como 'pense em inglês', 'aprenda com professores nativos', ou crenças como 'pra aprender tem que ir prá lá' [...], por exemplo, podem servir mais como fatores inibidores da motivação para o aprendiz do que facilitadores do processo de aprendizagem" (p. 124).

Viana, citado por Madeira, assevera: “[...] nenhuma dessas crenças têm fundamento: o aprendizado da "estrutura" da língua não depende do país onde se aprende, mas da abordagem utilizada; fluência e comunicação podem ser adquiridas fora do país onde se fala a LE e o ‘sotaque nativo’ é praticamente inatingível” (Viana, 1993 apud Madeira, p. 125). 
Barcelos (2007, p. 118-119) justifica que essa crença:

[...] pode ter a ver com o contexto socioeconômico no qual vivemos, onde pessoas importantes, pais e professores que admiramos transmitiram a mensagem que para ser respeitado e admirado como professor e aluno (identidade e emoção) é preciso falar assim e que é apenas "lá" que se aprende... é o mito do falante nativo, a valorização da temporada no exterior presente na sociedade brasileira, a adoração por tudo o que é estrangeiro (Barcelos, 2007, p. 118-119).

Há os convencidos de que o aprendizado de uma LE ocorre somente no país onde se fala essa LE, ao invés de numa sala de aula brasileira. Estando naquele país, com exposição no idioma constante, a aprendizagem seria facilitada, como se a mera exposição fosse suficiente garantia. Para Ferreira e Santos (2010, p. 128), "se alguém pensa que só se aprende uma segunda língua entre falantes fluentes, ou seja, no país em que se fala a língua-alvo, está equivocado".

Parigi (1978 apud Barcelos, 1995, p. 61-63) defende ser possível esse aprendizado apenas se o estudante dedicar-se muito para atingir seu objetivo pedagógico, mas o lugar não afasta as providências necessárias e complexas para se tornar um bilíngue.

Há a supervalorização do ingrediente "no exterior" ora como status, ora como condição de valoração do profissional do ensino da LE. Tal presunção, frequentemente, é reforçada pelo próprio professor, ao aconselhar seu aluno a fazer o mesmo, ou por escolas de idiomas, ao se promoverem sobre a experiência internacional de seus docentes.

Barcelos (1995, p. 105-106) chama isso de "mito", acrescido do fato de que entre os alunos, propaga-se outro mito: de que a linguagem que se aprende aqui não é a mesma usada pelos falantes nativos. Entende-se que não poderia sê-lo, por pelo menos duas razões: o fato de que a língua e o modo de falá-la são adaptados às reais condições de seu uso; e em razão de que em outros contextos haverá outros fatores, como a cultura, interferindo nos modos de falar. Portanto, trata-se de fato de um mito, inatingível, porque jamais existiria essa identidade desejada.

Madeira (2008, p. 124) relata que pesquisas já apontaram que nem sempre professores nativos são a melhor opção. O autor cita o trabalho de Consolo (1999), por exemplo, que constatou que, em aulas com professores falantes nativos, há maior uso da língua portuguesa do que nas aulas com professores brasileiros. 


\section{CONSIDERAÇÕES FINAIS}

A lista de crenças que colocamos à apreciação dos ingressantes de Letras circula aqui e ali no meio social que os rodeia. Aquelas nas quais eles demonstram acreditar mais estão, em parte, em sintonia com as contribuições da LA, mesmo não tendo sido ainda expostos a nenhuma delas no ambiente universitário.

A pergunta de pesquisa (quais as implicações das conjecturas sobre o ensino e a aprendizagem de LE, segundo a LA, mais assumidas por alunos do primeiro período do curso de licenciatura em Letras?) nos fez, consequentemente, refletir sobre a interferência dessas crenças no desempenho didático.

Nas avaliações feitas pelos participantes, há crenças que nada interferem ou por terem sido superadas ou por nunca terem sido objeto de verdade para esses alunos. Há algumas que exercem alguma influência, em menor escala. E, finalizando, há aquelas de alta relevância e sobre as quais expusemos pontos de vista de pesquisas científicas.

Todas as 25 crenças da listagem parecem ter sido construídas sobre algum fator específico que estaria envolvido e contribuiria para o resultado positivo no processo de ensinoaprendizagem da LE. Mas, consoante Lins Jr. (2006), há muitas crenças que mostram a ignorância social e a ausência de questionamento crítico.

Quando o fator específico é algo relacionado ao professor, algumas crenças depositam, em alguma característica do docente, a responsabilidade pelo sucesso do aprendizado da LE (crenças $\mathrm{n}^{\circ}$ 10, 14, 15, 17 e 23); outras, a algum fator associado ao conhecimento linguístico (3, $5,13,14,18,20$ e 25); a algum procedimento didático a ser adotado (6, 21, 22, 23 e 24); e à localização geográfica onde ocorreu sua formação docente (16 e 17) e o lugar onde o ensino ocorrerá $(4,7,8,9,10,11$ e 21$)$.

Quando o fator específico é algo relacionado ao estudante, algumas crenças atribuem o sucesso no ensino-aprendizagem da LE à situação econômica do estudante (crença n. ${ }^{\circ}{ }^{12}$ ), à idade (1), ao sexo (2), à localização geográfica onde ocorrerá o estudo (11, 16 e 17) ou uma determinada estratégia cognitiva a ser adotada (6).

Portanto, as 25 crenças expressam as seguintes conclusões: primeiro, para se ensinar e/ou aprender, o indivíduo precisa ter ou estar numa situação ideal para a garantia de ser bem sucedido no empreendimento com a LE. Segundo, todas depositam em um único fator toda a 
responsabilidade pelo ensino e/ou aprendizado da LE. Um ou outro fator vai sendo valorizado, conforme seu tempo de sobrevivência e significância durar, até se esgotar e outro fator assumir a condução de todo o trabalho docente, o que pode gerar um ciclo vicioso. Terceiro, não expressam a necessidade de qualquer esforço do indivíduo-aprendente, deixando todo o processo ensinoaprendizagem numa via de mão única: cabe ao professor (e somente a ele) a responsabilidade de "fornecer" e de fazer o aluno aprender a LE.

Acerca das crenças assumidas pela maioria dos ingressantes, quando o fator específico é algo relacionado ao professor, ou seja, alguma característica do docente ser a responsável pelo sucesso do ensino-aprendizado da LE, esses estudantes marcaram um procedimento didático a ser adotado (crença n. ${ }^{\circ} 21$ ), fatores associados ao conhecimento linguístico (18 e 25) e o lugar onde o ensino se realizará (10 e 11), que encontram respaldo nas conclusões dos estudos em LA. Entretanto, a maioria dos ingressantes também marcou um procedimento didático (crença n. ${ }^{\circ} 22$ ), um fator associado ao conhecimento linguístico (14) e uma estratégia cognitiva (6), que não se sustentam em contribuições teóricas LA.

Quando o fator específico é algo ligado ao estudante, os ingressantes marcaram algumas crenças que atribuem o sucesso no ensino-aprendizagem da LE ao lugar onde a aprendizagem ocorrerá (crença n. ${ }^{\circ} 11$ ), encontrando apoio na LA. Todavia, admitir a reponsabilidade do sucesso pelo fator idade (1) é uma crença controversa e defender a adoção de uma determinada estratégia cognitiva (6) não encontra respaldo nos estudos da LA.

\section{REFERÊNCIAS}

Aprendizagem. In: Houaiss, A. Dicionário eletrônico Houaiss da Língua Portuguesa. [S. 1.]: Objetiva, 2009. 1 CD-ROM. Versão monousuário 3.0 - Junho 2009.

Barcelos, A. M. F. A cultura de aprender língua estrangeira (inglês) de alunos de Letras. Dissertação (Mestrado em Lingüística Aplicada). UNICAMP, Campinas, 1995.

. Reflexões acerca da mudança de crenças sobre ensino e aprendizagem de línguas. Rev. Brasileira de Lingüística Aplicada, v. 7, n. 2, p. 109-138, 2007.

Cook, G. Applied linguistics: Oxford introductions to language study. Oxford: Oxford University Press, 2003.

Crença. In: Houaiss, A. Dicionário eletrônico Houaiss da Língua Portuguesa. [S. 1.]: Objetiva, 
2009. 1 CD-ROM. Versão monousuário 3.0 - Junho 2009.

Cruz, M. W. A pesquisa em sala de aula - interlocução entre teoria e prática: uma crítica na trama necessária. In: _ Faria, E. T. (orgs.). Aprender e ensinar: diferentes olhares e práticas. Porto Alegre: PUCRS, 2011. p. 26-41. Disponível em: $<$ http://ebooks.pucrs.br/edipucrs/Ebooks/Pdf/978-85-397-0076-9.pdf $>$. Acesso em: 14 dez 2016.

Dema, O., Moeller, A. K. Teaching culture in the 21st century language classroom. In: Touch the World: Selected Papers from the 2012 Central States Conference on the Teaching of Foreign Languages. Faculty Publications: Department of Teaching, Learning and Teacher Education, [s. 1.], p. 75-91, 2012. Paper 181. Disponível em: $<$ http://digitalcommons.unl.edu/cgi/viewcontent.cgi?article=1176\&context=teachlearnfacpub $>$. Acesso em: 10 dez 2016.

Education First. English Proficiency Index. [S. 1.: s. n.], 2015. Disponível em: $<$ http://media2.ef.com/_/ / media/centralefcom/epi/downloads/full-reports/v5/ef-epi-2015english.pdf $>$. Acesso em: 12 dez 2016.

Ensino. In: Houaiss, A. Dicionário eletrônico Houaiss da Língua Portuguesa. [S. 1.]: Objetiva, 2009. 1 CD-ROM. Versão monousuário 3.0 - Junho 2009.

Ferreira, I. K. S., Santos, L. F. A aprendizagem de língua estrangeira nos anos iniciais do Ensino Fundamental. Letrônica - Revista Digital do Programa de Pós-Graduação em Letras da PUC$R S \quad$-, $\quad$ v. 3, n. 1, p. 128-141, julho, 2010. Disponível em: $<\mathrm{http} / / /$ revistaseletronicas.pucrs.br/fo/ojs/index.php/letronica/article/view/6930/5468>. Acesso em: 9 dez 2016.

Florander, J., Jansen, M. Skolefors'g i engelsk 1959-1965. Copenhagen: Danish Institute of Education, 1968.

Genesee, F. Learning through two languages: Studies of immersion and bilingual education. New York: Newbury House, 1987.

Instituto de Pesquisas Plano CDE. O ensino de inglês na educação pública brasileira: elaborado com exclusividade para o British Council. São Paulo: British Council Brasil, 2014. Disponível em

https://www.britishcouncil.org.br/sites/default/files/estudo_oensinodoinglesnaeducacaopublicabr asileira.pdf. Acesso em: $12 \mathrm{dez} 2016$.

. O Ensino de Inglês na Educação Pública Brasileira: Elaborado com exclusividade para o British Council. São Paulo: British Council Brazil, 2015(b). Disponível em: $<$ https://www.britishcouncil.org.br/sites/default/files/estudo_oensinodoinglesnaeducacaopublicab rasileira.pdf $>$. Acesso em: $10 \mathrm{dez} 2016$.

Krashen, S., Long, M., Scarcella, R. Age, rate and eventual attainment in second language acquisition. Tesol Quarterly, n. 13, p. 573-582. 1979. 
Lenneberg, E. H. The biological foundations of language. New York: Wiley, 1967.

Lins Jr., J. R. F. Desmitificando a aprendizagem de língua estrangeira no ensino público brasileiro: o papel do professor de língua estrangeira numa perspectiva sócio-político-pedagógica. Revista do Programa Alfabetização Solidária, v. 1, p. 1, 2006. Disponível em: $<$ http://livrozilla.com/doc/1058152/desmitificando-a-aprendizagem-de-1\%C3\%ADnguaestrangeira>. Acesso em: 11 dez 2016.

Madeira, F. O sistema de crenças do aprendiz brasileiro de inglês: fatores que influenciam na construção de crenças. Trab. Ling. Aplic., Campinas, 47(1): 119-129, Jan./Jun. 2008.

Marzari, G. Q. O papel do gestor (professor) no desenvolvimento do programa institucional de bolsa de iniciação à docência - subprojeto letras: inglês/UNIFRA. InterLetras - Revista Transdisciplinar de Letras, Educação e Cultura da UNIGRAN, v. 3, ed. N. ${ }^{\circ}$ 17, abril-setembro 2013.

Disponível

em:

$<$ http://www.interletras.com.br/ed_anteriores/n17/conteudo/artigos/5.docx $>$. Acesso em $15 \mathrm{dez}$ 2016.

Moita Lopes, L. P. Oficina de lingüistica aplicada: a natureza social e educacional dos processos de ensino/aprendizagem de línguas. Campinas: Mercado de Letras, 2002. (Coleção Letramento, Educação e Sociedade).

Newport, E. Maturational constraints on language learning. Cognitive Science, n. 14, p. 11-28. 1990.

Oyama, S. A sensitive period for the acquisition of nonnative phonological system. Journal of Psycholinguistic Research, n. 5, p. 261-284. 1976.

Pinker, S. The Stuff of Thought. New York: Viking, 2007.

Pizzolato, C. E. A sala de aula de língua estrangeira com adultos de terceira idade. São Paulo: Unicamp, 1995.

Ramirez, J. D., Yuen, S. D., Ramey, D. R. Longitudinal study of structured English immersion strategy, early-exit and late-exit transitional bilingual education programs for language minority children. Final Report, v. 1 e 2. San Mateo-CA: Aguirre International, 1991.

Ramos, M. B. J. Autoestima: relação professor e aluno. In: ___ ; Faria, E. T. (orgs.). Aprender e ensinar: diferentes olhares e práticas. Porto Alegre: PUCRS, 2011. p. 42-56. Disponível em: $<$ http://ebooks.pucrs.br/edipucrs/Ebooks/Pdf/978-85-397-0076-9.pdf $>$. Acesso em: 14 dez 2016.

Romanelli, O. O. História da educação no Brasil (1930/1973). 30. ed. São Paulo: Vozes, 2003.

Terra, M. R. Um recorte do letramento em inglês no Brasil: o ponto de vista do aprendiz adulto. In: Rocha, C. H., Basso, E. A. (orgs). Ensinar e aprender lingua estrangeira nas diferentes 
idades. São Paulo: Claraluz, 2008, p.169-193.

\section{OS AUTORES}

Carmen Teresinha Baumgartner é docente da Universidade Estadual do Oeste do Paraná UNIOESTE, no programa de pós-graduação stricto sensu em Letras, membro do grupo de pesquisa "Linguagem, cultura e ensino".

E-mail: carmen.baumgartner@yahoo.com.br

Leandro Wallace Menegolo é discente da Universidade Estadual do Oeste do Paraná UNIOESTE, no programa de pós-graduação stricto sensu em Letras, membro do grupo de pesquisa "Linguagem, cultura e ensino".

E-mail: leandromenegolo@yahoo.com.br

Vitor Emanuel Sguarezi Marangoni é discente da Universidade Estadual do Oeste do Paraná UNIOESTE, no programa de pós-graduação stricto sensu em Letras, membro do grupo de pesquisa "Linguagem, cultura e ensino".

E-mail: vitorrv2@gmail.com 